\title{
Post COVID-19 syndrome in a prospective cohort study of Egyptian patients
}

\author{
Dalia Mohamed Gamal', Rehab Ali Ibrahim ${ }^{2^{*}}$ (1) and Sara Farid Samaan ${ }^{1}$
}

\begin{abstract}
Background: Post-coronavirus disease (COVID-19) syndrome is defined as the persistence of symptoms for more than 3 to 12 weeks after infection with the COVID-19 virus that cannot be attributed to another etiology. This study was conducted in our university hospital aiming to analyze the medium-term persistent symptoms in post-COVID-19 patients through a comprehensive and structured clinical assessment and evaluating the incidence, association, and risk factors of the post COVID-19 symptoms and their effect on the functional status of the survivors.

Results: Of 170 recruited individuals, about 66 (38.82\%) reported post-COVID-19 symptoms. Post-viral fatigue was the most common symptom (23.5\%), followed by arthralgia and myalgia in 32 patients (18.8\%). Lower functional status was reported among some of the survivors which can be attributed to the severity of the disease and the presence of post-COVID symptoms among these patients. The post-COVID-19 syndrome showed an association with patient age, severity of the disease, and the presence of preexisting comorbidities.

Conclusion: A significant functional impact was found in some COVID-19 survivors after COVID-19 infection. Age, severity of the disease, and presence of preexisting comorbidities are critical risk factors for the development of postCOVID-19 syndrome.
\end{abstract}

Keywords: Coronavirus, COVID-19, PCFS scale, Post COVID-19 syndrome

\section{Background}

The narrative of COVID-19 began in December 2019 in Wuhan, China, with a cluster of pneumonia patients of unclear etiology [1]. It quickly spread as an outbreak there and the National Health Commission of the Republic of China later stated that the outbreak was caused by a novel coronavirus now known as COVID-19. The virus was declared a pandemic by World Health Organization (WHO) on March 11, 2020 [2]. The disease has begun to spread around the world including Egypt. The first case was recorded in Egypt on February 14, 2020 [3]. Since then, Egypt has shown a gently rising trajectory up till now [4].

\footnotetext{
*Correspondence: rehab_ali_i@hotmail.com

${ }^{2}$ Department of Physical Medicine, Rheumatology and Rehabilitation,

Faculty of Medicine, Ain-Shams University, Cairo, Egypt

Full list of author information is available at the end of the article
}

Acute COVID-19 patients exhibited a wide range of symptoms ranging from minor respiratory symptoms to a severe type of pneumonia requiring mechanical ventilation and finally progressing to acute respiratory distress syndrome or multi-organ failure. Unfortunately, the fight against COVID-19 does not appear to end with the detection and treatment of acute disease. Studies have revealed a high incidence of persistent symptoms after acute infection in 40 to $90 \%$ of patients resulting in the term "long COVID-19" or "post COVID-19 syndrome" [5].

Because COVID-19 is a new virus, there is currently no agreement on the definition of post-COVID-19 syndrome. According to the National Institute for Health and Care Excellence (NICE), the Scottish Intercollegiate Guidelines Network (SIGN), and the Royal College of General Practitioners (RCGP), post COVID-19 was defined as "Signs and symptoms that arise during or following an infection compatible with COVID-19 that persist for more than 12 
weeks and are not explained by an alternative diagnosis" [6]. Greenhalgh et al. defined post-COVID syndrome as COVID-19-related disease that lasts longer than 3 weeks after the beginning of symptoms and chronic COVID19 as symptoms that last longer than 12 weeks after the onset of symptoms [7]. According to Amenta et al., for those who stay in the hospital at 3 weeks following symptom onset the post-acute phase begins when the patient is discharged from inpatient acute therapy [8]. Recently, the University of Cincinnati Medical Center's recommended criteria for COVID-19 sequelae; they divided long COVID-19 syndrome into five categories based on the initial symptoms, onset time, length of symptoms, and period of quiescence [9].

People with post-COVID-19 syndrome continued to experience one or more symptom such as generalized discomfort, exhaustion, persistently high temperature, and psychological issues. These symptoms do not just impact people who have had a bad case of the disease but can also affect people with mild course of the disease. Since the data of people experiencing long COVID-19 symptoms is still unclear [10], this study was conducted in our university hospital aiming to analyze the mediumterm persistent symptoms in post COVID-19 patients through a comprehensive and structured clinical assessment and evaluating the incidence, association, risk factors of the post COVID-19 symptoms, and their effect on the functional status of the survivors.

\section{Methods}

This single-center prospective cohort study was carried out at COVID-19 unit of Ain Shams university hospitals.

\section{Participants}

Patients with COVID-19 who presented to Ain Shams University hospitals triage and inpatient departments were screened for the study. Patients over the age of 18 with confirmed severe acute respiratory syndrome coronavirus 2 (SARS-CoV-2) positivity on reverse transcription polymerase chain reaction (RT-PCR) were eligible to participate. COVID-19 instances that were asymptomatic or critical, as well as individuals who refused to participate, were omitted from the study. All patients gave their informed written consent, after clinical recovery and viral clearance by two negative RT-PCR $48 \mathrm{~h}$ apart, the patients were monitored for at least one and a half month.

\section{Study design}

Patients' demographics, clinical signs and symptoms, comorbidities, and routine tests, such as complete blood count, C-reactive protein, creatinine, random blood sugar, alanine aminotransferase, and D-dimer, and high-resolution computed tomography chest (HRCT), were all suggested on enrolment. Patients were classified into 3 groups: mild, moderate, and severe. Mild disease was defined as symptoms of an upper respiratory tract viral infection, including mild fever, cough (dry), sore throat, nasal congestion, malaise, headache, muscle pain, anosmia, or malaise, according to $\mathrm{WHO}$ guidelines. Moderate disease was defined as respiratory symptoms such as cough and shortness of breath in the absence of indicators of severe pneumonia. Severe illness was defined as severe dyspnea and tachypnea (breathing rate of more than 30 breaths per minute). Clinical improvement was defined as normal body temperature for at least 3 days, significant improvement in respiratory symptoms (respiratory rate 25 breaths per minute and no dyspnea), oxygen saturation $(\mathrm{SpO} 2)>93 \%$ with no oxygen inhalation assistance, and no hospitalization for any pathology or clinician assessment [11]. All the patients were followed up in our post-COVID-19 clinic after one and half month for having persistent symptoms like fatigue, fever, dyspnea, and arthralgia, in addition to functional status assessment after COVID-19 infection using the Post COVID-19 Functional Status scale (PCFS) [12].

\section{Statistical analysis}

All data was gathered, tallied, and entered into IBM SPSS version 23 (released in 2015). Version 23.0 of IBM SPSS Statistics for Windows (Armonk, NY: IBM Corp.). Quantitative data with parametric distribution was displayed as mean, standard deviation, and ranges, but non-parametric data was displayed as median with inter-quartile range (IQR). Numbers and percentages were also used to represent qualitative characteristics. The chi-square test was used to compare the qualitative data of the two groups. The independent $t$ test was used to compare two independent groups with quantitative data and parametric distribution, while the Mann-Whitney test was used to compare two independent groups with non-parametric distribution. Univariate and multivariate logistic regression analysis was used to predict the risk factors for the occurrences of post COVID-19 symptoms and factors that affects the functional status with its odds ratio (OR) and 95\% confidence interval (CI). The confidence interval was set to $95 \%$ and the margin of error accepted was set to $5 \%$. So, the $p$ value was considered significant at the level of $P \leq 0.05$.

\section{Ethical consideration}

Approval of the study conduction was obtained from the Ethical Committee. Written informed consent was obtained from all participants. 


\section{Results}

This cohort Egyptian study was conducted on 170 patients, the median age of the participants was 57 years, there were 64 male patients and 106 female patients with male to female ratio 1:1.65, most of the patients had 1 or more comorbid diseases where 67 (39.4\%) patients were diabetic, 73 (42.9\%) were hypertensive, 25 (14.7\%) patients with ischemic heart disease (IHD), 5 (2.9\%) patients with cancer, 11 (6.5\%) patients with autoimmune diseases (AID), 12 (7.1\%) patients with stroke, $7(4.1 \%)$ patients with chronic renal failure (CRF), 8 (4.7\%) patients with chronic liver disease (CLD), and 9 (5.3\%) patients with chronic obstructed lung disease COPD (COPD) (Table 1).

At the time of initial presentation of the patients, 153 patients were presented with fatigue, 118 patients with fever, 117 patients with dyspnea, 127 patients with arthralgia and myalgia mainly in the form of low back pain, 122 patients with dry cough, 27 patients with anosmia, 13 patients with rhinitis, 55 patients with headache, 70 patients with chest tightness, 26 patients with sore throat, 20 patients with nausea, 18 patients with diarrhea, 12 patients with loss of taste, and finally 119 patients were diagnosed to have pneumonia with CT chest (Table 1).

As regard severity of the disease, 95 (55.9\%) patients were presented with mild disease, 47 (27.6\%) patients with moderate disease, and $28(16.5 \%)$ patients with severe disease according to WHO classification (Table 1).

\section{Post COVID-19 symptoms}

Among the 170 recruited patients, COVID-19 symptoms persisted beyond recovery for one and half months in about 66 (38.82\%). Post viral fatigue was the most prevalent persistent feature in about 40 patients, followed by arthralgia and myalgia in 32 patients in addition to other persistent symptoms as shown in Table 2.

To identify risk factors for the occurrence of post COVID-19 symptoms, we obtained the odds ratios (OR) after conducting the logistic regression analysis. The univariate analysis showed that increase age with $P<0.001$, presence of comorbidities (OR, 2.44; 95\% CI, 1.2-4.9; $P$ $=0.012$ ) were significantly associated with increased incidence of presence of post COVID-19 symptoms (Table 3).

\section{Post COVID-19 functional status}

Some patients reported reduction in function post COVID-19, in our study, functional status was assessed using the PCFS scale where 52 patients were found to be grade 1 (negligible limitation in everyday life, persistent
Table 1 Descriptive of demographic data, clinical characteristic, and severity of COVID-19 among our patients

\begin{tabular}{|c|c|c|}
\hline Parameter measured & No. & $\%$ \\
\hline \multicolumn{3}{|l|}{ Age } \\
\hline \multicolumn{3}{|c|}{ Mean $\pm S D, 55.46 \pm 16.07$} \\
\hline \multicolumn{3}{|l|}{ Median, 57 (45-67) } \\
\hline \multicolumn{3}{|l|}{ Range, (18-94) } \\
\hline \multicolumn{3}{|l|}{ Sex } \\
\hline Male & 64 & $37.6 \%$ \\
\hline Female & 106 & $62.4 \%$ \\
\hline \multicolumn{3}{|l|}{ Comorbidities } \\
\hline DM & 67 & $39.4 \%$ \\
\hline HTN & 73 & $42.9 \%$ \\
\hline$\| H D$ & 25 & $14.7 \%$ \\
\hline Cancer & 5 & $2.9 \%$ \\
\hline AID & 11 & $6.5 \%$ \\
\hline STROKE & 12 & $7.1 \%$ \\
\hline CRF & 7 & $4.1 \%$ \\
\hline CLD & 8 & $4.7 \%$ \\
\hline COPD & 9 & $5.3 \%$ \\
\hline \multicolumn{3}{|l|}{ COVID-19 symptoms } \\
\hline Fatigue & 153 & $90.0 \%$ \\
\hline Fever & 118 & $69.4 \%$ \\
\hline Dyspnea & 117 & $68.8 \%$ \\
\hline Arthralgia & 127 & $74.7 \%$ \\
\hline Myalgia & 127 & $74.7 \%$ \\
\hline Cough & 122 & $71.8 \%$ \\
\hline Anosmia & 27 & $15.9 \%$ \\
\hline Rhinitis & 13 & $7.6 \%$ \\
\hline Headache & 55 & $32.4 \%$ \\
\hline Chest tightness & 70 & $41.2 \%$ \\
\hline Sore throat & 26 & $15.3 \%$ \\
\hline Nausea & 20 & $11.8 \%$ \\
\hline Diarrhea & 18 & $10.6 \%$ \\
\hline Loss of taste & 12 & $7.1 \%$ \\
\hline \multicolumn{3}{|l|}{ COVID-19 severity } \\
\hline Mild & 95 & $55.9 \%$ \\
\hline Moderate & 47 & $27.6 \%$ \\
\hline Severe & 28 & $16.5 \%$ \\
\hline
\end{tabular}

$S D$ standard deviation, DM diabetes mellitus, $H T N$ hypertension, IHD ischemic heart disease, $A I D$ autoimmune disease, CLD chronic liver disease, CRF chronic renal failure, $C O P D$ chronic obstructive lung disease

symptoms, pain, depression, or anxiety), 41 patients with grade 2 (slight functional limitations), 15 patients with grade 3 (moderate functional limitation), and 2 patients with grade 4 (severe functional limitation) (Table 4).

To identify risk factors that may affect functional status, we obtained the odds ratios (OR) after conducting the logistic regression analysis. The univariate analysis 
Table 2 Descriptive of post COVID-19 clinical characteristics

\begin{tabular}{lll}
\hline Post COVID-19 symptoms & No. & $\%$ \\
\hline Fatigue & 40 & $23.5 \%$ \\
Fever & 4 & $2.4 \%$ \\
Dyspnea & 23 & $13.5 \%$ \\
Arthralgia & 32 & $18.8 \%$ \\
Myalgia & 32 & $18.8 \%$ \\
Cough & 8 & $4.7 \%$ \\
Anosmia & 2 & $1.2 \%$ \\
Rhinitis & 2 & $1.2 \%$ \\
Headache & 9 & $5.3 \%$ \\
Chest tightness & 17 & $10.0 \%$ \\
Sore throat & 0 & $0.0 \%$ \\
Nausea & 2 & $1.2 \%$ \\
Diarrhea & 1 & $0.6 \%$ \\
Loss of taste & 1 & $0.6 \%$ \\
\hline
\end{tabular}

of the patients was 55 years. Most of the patients initially presented with fatigue, followed by other symptoms such as fever, dyspnea, arthralgia, and myalgia as reported in earlier research [13].

According to Becker et al. [9] who classified COVID19 sequelae into five categories, type 2 was characterized by symptoms persisting 6 weeks from the onset of illness. So, after a one-and-a-half-month follow-up, we discovered that about $38.8 \%$ of the patients still had mild COVID-19 symptoms, which was consistent with many studies including one from the USA, which found that $35 \%$ of patients did not return to their previous health status even after 3 weeks of COVID-19 positivity [14]. Another prospective study by Carvalho-Schneider et al., done on 150 mild and moderate COVID-19 patients showed the presence of dyspnea and asthenia, respectively, in 30 and $40 \%$ of patients at 2 months of follow-up [15], which is partially consistent with our

Table 3 Logistic regression analysis for prediction of risk factors for post COVID-19 symptoms

\begin{tabular}{|c|c|c|c|c|c|c|}
\hline & \multicolumn{2}{|l|}{ Post COVID-19 symptoms } & \multirow[t]{3}{*}{ OR (95 Cl\%) } & \multicolumn{3}{|c|}{ Test of significance } \\
\hline & \multirow{2}{*}{$\begin{array}{l}\text { No } \\
\text { Mean } \pm \text { SD, } N \text { (row \%) }\end{array}$} & \multirow{2}{*}{$\begin{array}{l}\text { Yes } \\
\text { Mean } \pm \mathrm{SD}, N \text { (row \%) }\end{array}$} & & & & \\
\hline & & & & Value & $p$ value & Sig. \\
\hline Age & $51.54 \pm 16.35$ & $61.97 \pm 13.35$ & & $\boldsymbol{t}=-4.527$ & $<0.001$ & S \\
\hline \multicolumn{7}{|l|}{ Sex } \\
\hline Male & $39(60.94 \%)$ & $25(39.06 \%)$ & $0.908(0.48-1.7)$ & $X^{2}=0.088$ & 0.767 & NS \\
\hline Female & $67(63.21 \%)$ & 39 (36.79\%) & & & & \\
\hline \multicolumn{7}{|c|}{ Co-morbidities } \\
\hline No & $43(75.44 \%)$ & $14(24.56 \%)$ & $2.44(1.2-4.9)$ & $x^{2}=6.255$ & 0.012 & $S$ \\
\hline Yes & $63(55.75 \%)$ & $50(44.25 \%)$ & & & & \\
\hline
\end{tabular}

OR odd ratio, $\mathrm{Cl}$ confidence interval, $t$ student $t$ test value, $X^{2}$ chi square test value, statistical significance at $p \leq 0.05$

showed that increase age with $P<0.001$, presence of comorbidities (OR, 8.273; 95\% CI, 4.0-17.0; $P<0.001$ ) were significantly associated with poor functional status in patients with post COVID-19 symptoms (Table 5).

The functional status post COVID-19 was found to be affected by severity of the disease and with the presence of post COVID-19 symptoms with $p$ value $<0.001$ (Table 6).

\section{Discussion}

This study included 170 Egyptian patients diagnosed with acute COVID-19 syndrome recruited from Ain Shams University hospitals. We attempted to include patients with mild (59.5\%), moderate (27.6\%), and severe disease (16.5\%). The proportion of women with COVID-19 in our study was higher than that of men and the mean age
Table 4 Descriptive of post COVID-19 functional status scale in our patients after one and half months

\begin{tabular}{|c|c|c|c|c|}
\hline $\begin{array}{l}\text { Parameter } \\
\text { measured }\end{array}$ & Mean/N & SD \% & Median (IQR) & Range \\
\hline \multicolumn{5}{|c|}{ PCFS scale grade (after 1.5 months) } \\
\hline 0 & 60 & $35.3 \%$ & & \\
\hline 1 & 52 & $30.6 \%$ & & \\
\hline 2 & 41 & $24.1 \%$ & & \\
\hline 3 & 15 & $8.8 \%$ & & \\
\hline 4 & 2 & $1.2 \%$ & & \\
\hline $\begin{array}{l}\text { PCFS scale } \\
\text { grade (after } 1.5 \\
\text { months) }\end{array}$ & 1.10 & 1.02 & $1(0-2)$ & $(0-4)$ \\
\hline
\end{tabular}

PFCS Post COVID-19 Functional Status Scale, IQR interquartile range, SD standard deviation 
Table 5 Logistic regression analysis for prediction of risk factors that affect functional status in patients with post COVID-19 symptoms

\begin{tabular}{|c|c|c|c|c|c|c|}
\hline & \multicolumn{2}{|l|}{ PCFS (1.5 Months) } & \multirow[t]{3}{*}{ OR (95 Cl\%) } & \multicolumn{3}{|c|}{ Test of significance } \\
\hline & \multirow{2}{*}{$\begin{array}{l}\text { No } \\
\text { Mean } \pm \mathrm{SD}, N \text { (row \%) }\end{array}$} & \multirow{2}{*}{$\begin{array}{l}\text { Yes } \\
\text { Mean } \pm \mathrm{SD}, N(\text { row \%) }\end{array}$} & & & & \\
\hline & & & & Value & $p$ value & Sig. \\
\hline Age & $42.68 \pm 14.66$ & $62.44 \pm 12.05$ & & $\boldsymbol{t}=-8.923$ & $<0.001$ & $S$ \\
\hline \multicolumn{7}{|l|}{ Sex } \\
\hline Male & $24(37.5 \%)$ & $40(62.5 \%)$ & $1.167(0.61-2.2)$ & $X^{2}=0.219$ & 0.64 & NS \\
\hline Female & $36(33.96 \%)$ & 70 (66.04\%) & & & & \\
\hline \multicolumn{7}{|c|}{ Co-morbidities } \\
\hline No & $38(66.67 \%)$ & $19(33.33 \%)$ & $8.273(4.0-17.0)$ & $X^{2}=36.957$ & $<0.001$ & S \\
\hline Yes & $22(19.47 \%)$ & 91 (80.53\%) & & & & \\
\hline
\end{tabular}

OR odd ratio, $C l$ confidence interval, $t$ student $t$ test value, $X^{2}$ chi-square test value; statistical significance at $p \leq 0.05$

results where dyspnea and fatigue were persistent in $13.5 \%$ and $23.5 \%$ of our patients respectively. Another large study on 355 mild-to-severe COVID-19 patients reported that about $46 \%$ of patients had persistent post COVID-19 symptoms at 1 month of follow-up that were more evident in the female patient with fatigue being the main prevalent symptom going with the results of our study [16]. On the other side, an Italian study, Carf et al. [17] followed-up the patients with mild to severe disease who met the WHO criteria for discontinuation of quarantine (no fever for consecutive 3 days, improvement in other symptoms, and two negative test results for SARS-CoV-2, $24 \mathrm{~h}$ apart) and found that approximately $87 \%$ of the cases had persistence of at least one symptom, where the most common symptoms in the form of fatigue, dyspnea, joint, and chest pain respectively in $53.1 \%, 43.4 \%, 27.3 \%$, and $21.7 \%$ of patients at 2 months of follow-up, their results seem to be in line with ours where fatigue, arthralgia, dyspnea, and chest tightness were the most common persistent long-term symptoms.

Table 6 Relation between functional status with disease severity and the presence of post COVID-19 symptoms

\begin{tabular}{|c|c|c|c|c|c|}
\hline & \multicolumn{2}{|c|}{ PCFS post (1.5 months) } & \multicolumn{3}{|c|}{ Chi-square test } \\
\hline & \multirow{2}{*}{$\begin{array}{l}\text { No } \\
N \text { (row \%) }\end{array}$} & \multirow{2}{*}{$\begin{array}{l}\text { Yes } \\
N \text { (row \%) }\end{array}$} & & & \\
\hline & & & $x^{2}$ & $p$ value & Sig. \\
\hline \multicolumn{6}{|l|}{ Severity } \\
\hline Mild & $59(62.1 \%)$ & $36(37.9 \%)$ & 67.814 & $<0.001$ & S \\
\hline Moderate & $1(2.1 \%)$ & 46 (97.9\%) & & & \\
\hline Severe & $0(0.0 \%)$ & $28(100.0 \%)$ & & & \\
\hline \multicolumn{6}{|c|}{ Post COVID-19 symptoms } \\
\hline No & $50(83.33 \%)$ & $56(50.91 \%)$ & 17.388 & $<0.001$ & S \\
\hline Yes & $10(16.67 \%)$ & $54(49.09 \%)$ & & & \\
\hline
\end{tabular}

$X^{2}$ chi square test value, statistical significance at $p \leq 0.05$
Various studies have identified a variety of postCOVID-19 symptoms. According to our findings both patients with mild and severe instances of COVID19 can acquire post-COVID-19 symptoms. The most common post-COVID-19 symptom, following recovery according to most research, is chronic fatigue which is followed by cough, dyspnea, and widespread musculoskeletal pain [18]. Based on a recent systematic review by Salamanna et al., chronic fatigue is clearly considered the most common long-term symptom in mild-to-severe COVID-19 patients [19]. Fatigue, post-exercise dyspnea, and persistent musculoskeletal discomfort were found in $23.5 \%, 13.5 \%$, and $18.8 \%$ of the participants in our study respectively. The cause of fatigue predominance was mostly unknown, several investigations have shown that immune system changes caused by viral infections may be the cause of weariness by triggering an inflammatory immune response $[19,20]$. Therefore, it might be necessary to examine cytokine networks in COVID-19 survivors to see if the "cytokine storm" that occurred during the disease remains and contributes to these long-term problems. Several studies have demonstrated persistent HRCT lung abnormalities after 60 days from the initial presentation. A decreased diffusion capacity due to loss of lung volume is the most commonly reported pathophysiologic impairment in post-acute effects of COVID-19 which is directly related to the severity of acute illness [21].

Some of prior studies failed to identify risk factors for post-COVID-19 syndrome, according to the current study even patients with modest symptoms at the time of presentation can acquire post-acute COVID19 symptoms, there was a strong association between post-COVID-19 syndrome and age of the patients, existence of underlying comorbidities and severity of the condition. 
Functional status among COVID-19 survivors exhibited affection may be due to persistence of post COVID-19 symptoms. In our study, we used the PCFS scale to assess functional status among COVID-19 survivors one and a half month after initial infection. We found that 52 patients were grade 1 (negligible limitation), 41 patients were grade 2 (slight limitation), 15 patients were grade 3 (moderate limitation), and 2 patients were grade 4 (severe limitation).

Lower functional status was found to have a statistically significant relationship with patient age, disease severity, presence of post COVID-19 symptoms, and finally the presence of preexisting comorbidities. This was partially in accordance with the results of Hussein et al., who found significant association of PCFS with age and presence of comorbidities [22]. Our study findings revealed that respondents with chronic medical conditions (HTN, DM, IHD, cancer, arthritis) reported significantly lower functional status scores. Our findings are in line with those of a Moroccan study, which found that the COVID19 pandemic had a mostly negative impact on QOL and well-being of those with chronic medical conditions [23]. Another study also supported the vulnerability of individuals with chronic medical problems to experience poor quality of life during the first wave of COVID-19, which explains the finding that "chronic illness or a selfevaluation of poor health is associated with increased psychological distress" [24].

This study has strengths as being one of the few studies done to assess functional status and long-term dysfunction among post COVID-19 survivors using a validated, specific, and an easy tool that can be easily applied to the patients which is the PCFS. In addition, our study identifies the most prevalent long-term symptoms which might impede return to pre-COVID-19 infection functional capacity. Our study has some limitations. First, it is a single center study. Second, the follow-up period for patients was limited ( 1 and half months after disease onset) and third, the small sample size. Further longitudinal studies are recommended to assess the longterm effect of COVID-19 infection and the association between the persistence of long-term symptoms and proinflammatory cytokines.

\section{Conclusions}

We found that some COVID-19 survivors reported a significant impact on their functional status after the virus. Age, disease severity, and the existence of pre-existing comorbidities are all important risk factors for developing post-COVID-19 syndrome.

\section{Abbreviations}

AID: Autoimmune diseases; CLD: Chronic liver disease; COPD: Chronic obstructed pulmonary disease; COVID: Coronavirus disease; CRF: Chronic renal failure; DM: Diabetes mellitus; HRQHRCT: High-resolution computed tomography; HTN: Hypertension; IHD: Ischemic heart disease; PCFS: Post COVID-19 Functional Status Scale; RT_PCR: Reverse transcriptase polymerase chain reaction; SARS: Severe acute respiratory syndrome; WHO: World Health Organization.

\section{Acknowledgements}

Not applicable.

\section{Authors' contributions}

Study design was done by Dr. DMG and Dr. SFS. Data collection and interpretation, manuscript writing, and editing were done by Dr. DMG, Dr. RAI, and Dr. SFS. All authors have read and approved the manuscript.

Funding

The study has no funding from any resource.

Availability of data and materials

All data generalized and/or analyzed during the current study are available with principal author upon reasonable request.

\section{Declarations}

Ethics approval and consent to participate

This study was approved by the Ain Shams University, Faculty of Medicine Research Ethics Committee (REC) FWA 000017585. FMASU R140/2021. A written informed consent was obtained from patients sharing in the study.

\section{Consent for publication}

Not applicable.

\section{Competing interests}

The corresponding author is also an associate editor in Egyptian Rheumatology and Rehabilitation Journal.

\section{Author details}

${ }^{1}$ Department of Internal Medicine, Faculty of Medicine, Ain-Shams University, Cairo, Egypt. ${ }^{2}$ Department of Physical Medicine, Rheumatology and Rehabilitation, Faculty of Medicine, Ain-Shams University, Cairo, Egypt.

Received: 7 October 2021 Accepted: 1 December 2021

Published online: 02 February 2022

\section{References}

1. Centers for Disease Control and Prevention. (2019) Novel coronavirus, Wuhan, China. Information for Healthcare Professionals. https://www.cdc. gov/coronavirus/2019-nCoV/hcp/index.html (Accessed August 2021).

2. WHO Director-General's opening remarks at the media briefing on COVID-19. https://www.who.int/dg/speeches/detail/who-director-gener al-s-opening-remarks-at-the-media-briefing-on-COVID-19\%2D\%2D-11march-2020 (Accessed August 2021).

3. Medhat MA, Kassas ME (2020) COVID-19 in Egypt: uncovered figures or a different situation? J Glob Health 10(1):010368

4. Updates on COVID-19 (coronavirus disease- 2019) local situation. https:// www.moh.gov.eg/COVID-19 (Accessed August 2021).

5. Wang $X, X u$ H, Jiang H, Wang L, Lu C, Wei X, Liu J, Xu S (2020) Clinical features and outcomes of discharged coronavirus disease 2019 patients: a prospective cohort study. QJM Mon J Assoc Physicians 113:657-665

6. Shah W, Hillman T, Playford ED, Hishmeh L (2021) Managing the long term effects of covid-19: summary of NICE, SIGN, and RCGP rapid guideline. BMJ 372:n136

7. Greenhalgh T, Knight M, A'Court M, Buxton M, Husain L (2020) Management of post-acute COVID-19 in primary care. BMJ 370:m3026 
8. Amenta EM, Spallone A, Rodriguez-Barradas MC, El Sahly HM, Atmar RL, Kulkarni PA (2020) Post-acute COVID-19: an overview and approach to classification. Open Forum Infect Dis 7(12):ofaa509

9. Becker RC (2021) COVID-19 and its sequelae: a platform for optimal patient care, discovery, and training. J Thromb Thrombolysis 51(3):587-594

10. Li LQ, Huang T, Wang YQ, Wang ZP, Liang Y, Huang TB, Zhang HY, Sun W, Wang Y (2020) COVID-19 patients' clinical characteristics, discharge rate, and fatality rate of meta-analysis. J Med Virol 92:577-583 doi: 10.1002/ jmv.25757PubMedGoogle Scholar

11. Guan WJ, Ni ZY, Hu Y, Liang WH, Ou CQ, He JX, Liu L, Shan H, Lei CL, Hui DSC, Du B, Li LJ et al (2020) Clinical characteristics of coronavirus disease 2019 in China. N Engl J Med 382:1708-1720

12. Klok FA, Boon GJAM, Barco S, Endres M, Geelhoed JJM, Knauss S, Rezek SA, Spruit MA, Vehreschild J, Siegerink B (2020) The Post-COVID-19 Functional Status scale: a tool to measure functional status over time after COVID-19. Eur Respir J 56:2001494. https://doi.org/10.1183/13993003. 01494-2020

13. Grant MC, Geoghegan L, Arbyn M, Mohammed Z, McGuinness L, Clarke $E L$, Wade RG et al (2020) The prevalence of symptoms in 24,410 adults infected by the novel coronavirus (SARS-CoV-2; COVID-19): a systematic review and meta-analysis of 148 studies from 9 countries. PLoS One 15(6):e0234765 pmid: 32574165

14. Tenforde MW, Kim SS, Lindsell CJ, Rose EB, Shapero NI, Files C, Gibbs KW, Erickson HL, Steingrub JS, Smithline HA, Gong MN, Aboodi MS, Exline MC, Henning DJ, Wilson JG, Khan A, Qadir N, Brown SM, Peltan ID, Rice TW, Hager DN, Ginde AA, Stubblefield WB, Patel MM, Self WH, Feldstein LR, IVY Network Investigators; CDC COVID-19 Response Team (2020) Symptom duration and risk factors for delayed return to usual health among outpatients with COVID-19 in a multistate health care systems network: United States, March-June 2020. MMWR Morb Mortal Wkly Rep 69(30):993-998 pmid:327302

15. Carvalho-Schneider C, Laurent E, Lemaignen A, Beaufils E, Bourbao-Tournois C, Laribi S et al (2020) Follow-up of adults with noncritical COVID-19 two months after symptom onset. Clin Microbiol Infect 27:258-263. https://doi.org/10.1016/j.cmi.2020.09.052

16. Mahmud R, Rahman M, Rassel MA, Monayem FB, Sayeed SJB, Islam MS, Islam MM (2021) Post COVID syndrome among symptomatic COVID-19 patients: a prospective study in a Tertiary Care Center in Bangladesh. PLoS One 16(4):e0249644

17. Carfi A, Bernabei R, Landi F, for the Gemelli against COVID-19 Post-Acute Care Study Group (2020) Persistent symptoms in patients after acute COVID-19. JAMA. 324(6):603-660 pmid:32644129

18. Del Rio C, Collins LF, Malani P (2020) Long-term health consequences of COVID-19. JAMA. 324(17):1723-1724 pmid:33031513

19. Salamanna F, Veronesi F, Martini L, Landini MP, Fini M (2021) PostCOVID-19 syndrome: the persistent symptoms at the post-viral stage of the disease. A Systematic Review of the Current Data. Front Med (Lausanne) 4(8):653516

20. Moldofsky H, Patcai J (2011) Chronic widespread musculoskeletal pain, fatigue, depression and disordered sleep in chronic post-SARS syndrome: a case-controlled study. BMC Neurol 11:1-7 Pmid: 21208452

21. Huang Y, Tan C, Wu J, Chen M, Wang Z, Luo L, Zhou X, Liu X, Huang X, Yuan S, Chen C, Gao F, Huang J, Shan H, Liu J (2020) Impact of coronavirus disease 2019 on pulmonary function in early convalescence phase. Respir Res 21(1):163

22. Hussein AAM, Saad M, Zayan HE, Abdelsayed M, Moustafa M, Ezzat AR, Helmy R, Abd-Elaal H, Aly K, Abdelrheem S, Sayed I (2021) Post-COVID-19 functional status: relation to age, smoking, hospitalization, and previous comorbidities. Ann Thorac Med 6(3):260-265

23. Qiu J, Shen B, Zhao M, Wang Z, Xie B, Xu Y (2020) A nationwide survey of psychological distress among Chinese people in the COVID-19 epidemic: implications and policy recommendations. Gen Psychiatry 33:e100213

24. Hawryluck L, Gold WL, Robinson S, Pogorski S, Galea S, Styra R (2004) SARS control and psychological effects of quarantine, Toronto. Canada Emerg Infect Dis 10:1206-1212

\section{Publisher's Note}

Springer Nature remains neutral with regard to jurisdictional claims in published maps and institutional affiliations.

\section{Submit your manuscript to a SpringerOpen ${ }^{\circ}$ journal and benefit from:}

- Convenient online submission

- Rigorous peer review

- Open access: articles freely available online

- High visibility within the field

- Retaining the copyright to your article

Submit your next manuscript at $\boldsymbol{\nabla}$ springeropen.com 